\title{
Povos e comunidades tradicionais em Santa Catarina: sistematização de dados e reflexão sobre conflitos ambientais territoriais
}

\author{
Diego da Silva Grava \\ Universidade Regional de Blumenau - Blumenau - SC - Brasil \\ ORCID: https://orcid.org/0000-0003-4879-5474 \\ Luciano Félix Florit \\ Universidade Regional de Blumenau - Blumenau - SC - Brasil \\ ORCID: https://orcid.org/0000-0001-5437-8234
}

\section{Resumo}

O presente artigo apresenta um levantamento sobre os povos e comunidades tradicionais em Santa Catarina (SC) e identifica a existência de situações de conflitos ambientais envolvendo seus territórios. Analisamos e sistematizamos dados dispersos reunidos a partir de revisão bibliográfica (teses, dissertações, artigos, dados secundários oficiais e extraoficiais, dentre outros) e realizamos uma reflexão crítica, à luz das perspectivas da Ecologia Política e da Justiça Ambiental, sobre sua situação em SC. Nesse sentido, o trabalho visa identificar os povos e comunidades tradicionais existentes em SC, quem são, onde se localizam, se enfrentam ou já enfrentaram situações de conflitos ambientais. Com o estudo, foi possível verificar que existe em SC uma grande diversidade de atores que podem ser considerados povos e comunidades tradicionais e que, em geral, enfrentam situações de vulnerabilidade socioeconômica e vivenciam ou já vivenciaram conflitos relacionados aos seus territórios. A existência de conflitos ambientais territoriais envolvendo povos e comunidades tradicionais parece um fenômeno comum e recorrente em SC.

Palavras-chave: Povos e comunidades tradicionais. Conflitos ambientais territoriais. Conflitos de valoração. Santa Catarina. Brasil.

\section{Traditional peoples and communities in Santa Catarina: data systematization and} reflection on territorial environmental conflicts

\section{Abstract}

This article presents a survey of traditional peoples and communities in Santa Catarina state (SC) and identifies the existence of situations of environmental conflicts involving their territories. We analyzed and systematized dispersed data gathered from bibliographic review (theses, dissertations, papers, official and unofficial secondary data, among others) and carried out a critical reflection, based on the perspectives of Political Ecology and 
Environmental Justice, about their situation in SC. In this sense, the work aims to identify the traditional peoples and communities existing in SC, who they are, where they live, if they face or have faced situations of environmental conflicts. With the study, it was possible to verify that there is a great diversity of actors in SC that can be considered traditional peoples and communities and that, in general, they face situations of socioeconomic vulnerability and experience or have experienced conflicts related to their territories. The existence of territorial environmental conflicts involving traditional peoples and communities seems to be a common and recurring phenomenon in SC.

Keywords: Traditional peoples and communities. Territorial environmental conflicts. Valuation conflicts. Santa Catarina. Brazil.

\section{Pueblos y comunidades tradicionales en Santa Catarina: sistematización de datos y reflexión sobre conflictos ambientales territoriales}

\section{Resumen}

El artículo presenta una un estudio amplio respecto los pueblos y comunidades tradicionales en el Estado de Santa Catarina (SC) e identifica la existencia de situaciones de conflictos ambientales que involucran a sus territorios. Analizamos y sistematizamos datos dispersos recopilados por medio de revisión bibliográfica (tesis, disertaciones, artículos, datos secundarios oficiales y no oficiales, entre otros) y realizamos una reflexión crítica, a la luz de las perspectivas de la Ecología Política y la Justicia Ambiental, sobre su situación en SC. En este sentido, el trabajo tiene como objetivo identificar a los pueblos y comunidades tradicionales existentes en SC, quiénes son, dónde se encuentran, si enfrentan o ya han enfrentado situaciones de conflicto ambiental. Como resultado, fue posible verificar que existe una gran diversidad de actores en SC que se pueden considerar pueblos y comunidades tradicionales y que, en lo general, enfrentan situaciones de vulnerabilidad socioeconómica y han experimentado conflictos relacionados con sus territorios. La existencia de conflictos ambientales territoriales que involucran a pueblos y comunidades tradicionales parece ser un fenómeno común y recurrente en SC.

Palabras clave: Pueblos y comunidades tradicionales. Conflictos ambientales territoriales. Conflictos de valoración. Santa Catarina. Brasil.

\section{Introdução}

A expansão das fronteiras agropecuárias, minerais e energéticas, impulsionadas pelo processo de valorização das commodities, embora com oscilações, levou a um processo de reprimarização da economia brasileira. Isto ocorreu ao compasso de um fenômeno semelhante na América Latina, que fez com que atores dominantes ou hegemônicos, agentes públicos e privados, passassem a fazer incursões em territórios tradicionais a fim de se apropriar dos recursos naturais aí existentes (MARTINS, 2009; NEGRI; ALVARENGA, 2011; CANO, 2012; NASSIF, 2012; CEPAL, 2012; GUDYNAS, 2012; SVAMPA, 2013).

Essas incursões, legais ou não, ensejaram conflitos em várias regiões do território brasileiro. Somente no estado de Minas Gerais, o Grupo de Estudos em Temáticas Ambientais (GESTA/UFMG), por meio do Observatório de Conflitos Ambientais ([OCA] 2010), registrou, até 2010, mais de 500 conflitos ambientais. O mapeamento mais abrangente sobre este tipo de conflito foi realizado pela Fundação Oswaldo Cruz [FIOCRUZ]. Até abril de 2020, a FIOCRUZ (sem data) tinha registrado mais de 600 casos de "conflitos envolvendo injustiça ambiental e saúde no Brasil". O mapeamento da FIOCRUZ descreve os atores envolvidos, as principais 
causas e os efeitos dos conflitos. Certamente, considerando a dinâmica dos conflitos e o desenrolar das políticas ambientais dos últimos anos (ver, por exemplo, SILVA, 2020), o número de casos possivelmente é muito maior.

Indígenas, agricultores familiares, quilombolas, pescadores artesanais e ribeirinhos, alguns dos grupos que compõem os povos e comunidades tradicionais, são os mais atingidos. Os conflitos se dão majoritariamente sobre territórios tradicionais, ocasionando a alteração no regime de uso e ocupação, inviabilizando modos de vida, e em muitos casos, provocando a expulsão ou o reassentamento compulsório dessas populações. As principais atividades ligadas aos conflitos são o agronegócio, a mineração, a construção de barragens e hidrelétricas e a pecuária (FIOCRUZ, 2010). Essas afirmações são corroboradas por inúmeras constatações realizadas por diferentes pesquisadores e grupos de pesquisa que acompanham a situação desses povos nos últimos anos.

Em Santa Catarina, estado conhecido no senso comum por ser constituído majoritariamente por uma população branca de descendência europeia, verificamos a existência de conflitos semelhantes. No estado, diversos grupos sociais considerados "Povos e Comunidades Tradicionais" permanecem invisibilizados e enfrentam situações de conflito envolvendo acesso aos recursos, perda e disputas em relação ao território, degradação ambiental de seus territórios tradicionais, dentre outros obstáculos.

Ainda que exista inúmeros trabalhos sobre este tema, são escassas as análises abrangentes que tratem do conjunto dos povos e comunidades tradicionais nesse estado. Nesse contexto, torna-se muito relevante construir um olhar que abarque os diversos povos e comunidades tradicionais que vivem em SC, conferindo algumas de suas características socioeconômicas e verificando os principais conflitos ambientais territoriais que enfrentam ou já enfrentaram.

Por meio da análise e sistematização de dados dispersos (sobre quem são os grupos, onde se localizam, que tipo de conflitos enfrentam ou já enfrentaram, situação socioeconômica, etc.), reunidos a partir de revisão bibliográfica (teses, dissertações, artigos, relatórios técnicos, sítios especializados, como o do Instituto Socioambiental, dados secundários oficiais e extraoficiais, como os do IBGE e da FUNAI), oferecemos um panorama geral sobre os povos e comunidades tradicionais em Santa Catarina, e propomos uma discussão desta realidade sob o prisma da Ecologia Política e da Justiça Ambiental.

Verificamos que existe em Santa Catarina uma grande diversidade de grupos sociais que podem ser considerados povos e comunidades tradicionais, que, em geral, enfrentam situações de vulnerabilidade socioeconômica e vivenciam ou já vivenciaram conflitos relacionados aos seus territórios. Esses conflitos muitas vezes implicam, também, em conflitos de valoração, nos quais as formas de valorar a natureza e os recursos são incompatíveis com a realizada pelos atores que expressam a territorialidade urbana industrial capitalista.

Santa Catarina é um estado que tende a se auto representar fundamentalmente como de descendência europeia e de grande homogeneidade territorial. Entretanto, este estudo mostra, por um lado, uma heterogeneidade de situações nas quais grupos sociais específicos são invisibilizados e têm seus direitos negligenciados, e são invisíveis para boa parte das políticas públicas e os padrões de desenvolvimento dominantes. Por outro lado, evidenciamos que esses mesmos 
grupos apresentam uma enorme riqueza sociocultural, que é ambientalmente relevante ao se pensar o desenvolvimento territorial no estado.

\section{A Categoria de Povos e Comunidades Tradicionais}

A definição de "Povos e Comunidade Tradicionais" (PCT) tem aspectos jurídicos, científicos e políticos. No Decreto $n^{\circ} 6.040 / 2007$, os povos e comunidades tradicionais foram definidos como:

[...] grupos culturalmente diferenciados e que se reconhecem como tais, que possuem formas próprias de organização social, que ocupam e usam territórios e recursos naturais como condição para sua reprodução cultural, social, religiosa, ancestral e econômica, utilizando conhecimentos, inovações e práticas gerados e transmitidos pela tradição (BRASIL, 2007).

Trata-se de uma categoria abrangente, que inclui inúmeras denominações identitárias e modos de vida que têm se criado ao longo dos séculos nas nuances do território nacional. Dentre eles, os povos indígenas têm direitos territoriais amparados no artigo $231^{\circ}$ da CF88 (BRASIL, 1988), e os quilombolas têm direitos territoriais amparados no artigo $68^{\circ}$ do Ato das Disposições Constitucionais Transitórias da CF88 (ibidem). Outras denominações, como vazanteiros, faxinalenses, ribeirinhos, etc., não contam com esse amparo jurídico específico ${ }^{1}$.

Para Cunha e Almeida (2001), a categoria se refere a grupos que têm histórico de baixo impacto ambiental e possuem interesse em manter e controlar os territórios que exploram prestando serviços ambientais ao manter este controle. Além disso, tendem a apresentar formas mais equitativas de organização social, lideranças locais, representação institucional e traços culturais que são reelaborados e reafirmados continuamente.

Brandão (2015) segue o mesmo raciocínio, reafirmando algumas das características observadas por Cunha e Almeida (2001) e incluindo outras, como a memória de resistência, principalmente com referência a processos ligados ao território, como ameaça, expulsão e expropriação.

Esses grupos não são necessariamente homogêneos entre si. A categoria de povos indígenas, por exemplo, abriga uma infinidade de grupos, totalizando cerca de 305 etnias e 274 línguas diferentes, de acordo com o "Censo Demográfico 2010" (INSTITUTO BRASILEIRO DE GEOGRAFIA E ESTATÍSTICA, 2010a). O mesmo acontece com outras denominações, havendo uma diversidade interna significativa ${ }^{2}$.

No âmbito acadêmico, a definição "povos (ou populações) e comunidades tradicionais", talvez por sua amplitude, levou alguns autores a serem críticos ou a fazerem ressalvas ao uso da categoria (DIEGUES, 2000b; LITTLE, 2004; BRANDÃO, 2015; FILHO, 2015). Nesse sentido, entendemos ser importante trazer a distinção, enfatizada por Brandão (2015), entre sociedade e comunidade. A sociedade seria o lugar mais abstrato, abrangente, institucional, contratual e impositivo, enquanto a

\footnotetext{
1 Uma lista completa das denominações consideradas Povos e Comunidades Tradicionais é apresentada em Brasil, 2016.

${ }^{2}$ Vale observar que essas denominações também não são sempre mutuamente excludentes. Por exemplo, há vazanteiros que são quilombolas e são pescadores.
} 
comunidade seria o lugar do concreto, delimitado, interpessoal, consensual, com experiências de liberdade que seriam impensáveis se estivessem submetidos às regras da sociedade envolvente (BRANDÃO, 2015).

As comunidades tradicionais seriam uma contraposição à sociedade moderna, implicando em uma lógica de organização social distinta, com características próprias, resguardando certa autonomia, caracterizada por uma forma de sociabilidade diferente daquela que impera nas sociedades modernas, muito vinculadas à razão instrumental. Daí a importância da distinção enfatizada por Brandão (2015) entre sociedade e comunidade. Ela nos ajuda a perceber que as dinâmicas dos "povos e comunidades tradicionais" mantém uma relação diferenciada com o meio natural que, pela sua sustentabilidade intrínseca e pela sua contraposição à sociedade envolvente, contribuem para formas de desenvolvimento territorial mais plurais. Sua relação diferenciada costuma ser, de fato, uma resistência ao avanço do uso predatório da natureza de forma meramente instrumental, evidenciando usos dos recursos naturais disponíveis em um dado território sem que se esgote sua capacidade de regeneração.

Considerando a contribuição de vários autores, apresentamos um resumo das principais características dos povos e comunidades tradicionais (BRASIL, 2007; DIEGUES, 2000B; LITTLE, 2004; CUNHA; ALMEIDA, 2001; BRANDÃO, 2015; FILHO, 2015):

- Autorreconhecimento

- Conexão forte com o território

- Conhecimentos e práticas transmitidos pela tradição

- Dependência dos recursos naturais para reprodução material e social

- Diferenciação cultural

- Histórico de baixo impacto ambiental

- Lideranças locais

- Ligação diferenciada com o mercado

- Memória de resistência (ligada à permanência no território)

- Organização social mais equitativa do que a da sociedade envolvente

- Reduzida acumulação de capital

- Representação institucional própria, que faz valer suas regras

- Trabalho "informal"

- Traços culturais reelaborados e reafirmados continuamente

Embora utilizada rotineiramente, nestas comunidades a natureza em geral não é vista apenas de modo instrumental, fazendo parte do seu círculo de consideração moral. Dessa forma, essas populações têm contribuído para a manutenção da qualidade ambiental de seus territórios através da manutenção de práticas tradicionais que vêm se reinventando diante do fenômeno da modernidade, estabelecendo alianças e conflitos com diversos atores buscando manter o controle sobre seus territórios e a manutenção de seus modos de vida, cada vez mais ameaçados pela expansão da territorialidade urbana industrial capitalista. 


\section{Povos e Comunidades Tradicionais em Santa Catarina}

O trabalho se baseou em levantamento e revisão bibliográficos (análise documental), complementados com contatos diretos com alguns pesquisadores e autores e com visitas a três comunidades. A pesquisa foi realizada entre julho de 2017 e junho de 2019. Foram realizadas consultas a teses, dissertações, artigos científicos, legislação, buscadores como Google e Google Scholar, revistas Scielo, anais de eventos de várias áreas (Desenvolvimento Regional, Sociologia, Antropologia e Geografia), e programas de pós-graduação (Desenvolvimento Regional, Ciências Ambientais, Antropologia, Sociologia e Geografia) e grupos de pesquisa (citados na Introdução). O Censo de 2010 do IBGE, os sítios da FUNAI, da Comissão Pró-Índio de São Paulo, da Fundação Cultural Palmares, também forneceu algumas informações quantitativas e qualitativas relevantes sobre os povos indígenas (dados socioeconômicos, sobre terras demarcadas ou em processo de demarcação, etc. Foram realizadas saídas a campo junto a cinco comunidades: indígenas Xokleng-Laklãnõ, em Doutor Pedrinho; Cipozeiros, em Garuva; e indígenas Guarani, em Major Gercino; Comunidade Quilombola São Roque, em Praia Grande; e Faxinais/Caívas, Comunidade Aparecida dos Pardos, em Irineópolis (também foram visitados faxinais do munícipio de Pinhão, no Paraná). Essas saídas a campo estão relacionadas a estudos de caso em andamento e não visaram obter dados específicos para este artigo. Contudo, elas foram muito importantes para obter uma perspectiva in loco da realidade, o que facilitou a aproximação e compreensão dos dados secundários.

Como resultado desta pesquisa, identificamos referências aos seguintes grupos em Santa Catarina: Açorianos; Cafuzos/Caboclos; Cipozeiros; Quilombolas; Faxinalenses/Caívas; Pescadores Artesanais; Pomeranos; Povos Indígenas (Guarani, Kaingang, Xokleng-Laklãnõ).

Bustamante et al, (2015) também caracteriza os Agricultores Familiares como comunidade tradicional. Todavia, considerando que muitos agricultores familiares estão fortemente integrados à agroindústria e ao mercado, essa inclusão está aberta à discussão. Notamos que, mais do que uma identidade, a agricultura familiar é uma das características ou práticas de muitas comunidades tradicionais, como quilombolas, cafuzos, faxinalenses/caívas, entre muitos outros.

Três Povos Indígenas se fazem presentes em Santa Catarina: Kaingang, Xokleng-Laklãnõ e Guarani (M’bya e Nhandeva/Chiripá). Estão distribuídas em 29 Terras Indígenas ( $\mathrm{TI}$ ) em diferentes estágios de reconhecimento (FUNAI, sem data). As $\mathrm{TI}$ estão concentradas, principalmente, nas regiões oeste, norte e no litoral de SC.

Importante lembrar que, também nesse estado, o contato entre europeus e nativos foi marcado, desde o início, pelo conflito, que começa com a invasão das terras, em 1728, com a abertura da estrada de tropas, que ligava o Rio Grande do Sul a São Paulo. Posteriormente, intensificando-se com a ocupação a partir do século XIX, a declaração de guerra aos Xokleng-Laklãnõ por Dom João VI, pela Carta Régia de 5 de novembro de 1808, e com a criação de diversos mecanismos para a ocupação do território indígena, como a atração de imigrantes europeus (FLORIT et al, 2016). 
Um conflito territorial emblemático, envolvendo os três povos (e que também chegou a envolver a comunidade (afuza) e se estende por um longo período até o presente, tem lugar na Terra Indígena Ibirama (Reserva Duque de Caxias), no Alto Vale do Itajaí. A reserva, que abriga as três etnias existentes em SC, sendo a Xokleng-Laklãnõ a mais numerosa (FUNAI, sem data), foi oficializada em 1926 por meio do Decreto Estadual $N^{0} .15$ de 3 de abril, reconhecendo aos indígenas o direito a 14 mil hectares de terra.

No entanto, a Barragem Norte, construída entre 1972 e 1992 especificamente para a contenção de cheias em outras regiões da bacia, a jusante (ATHAYDE; MARTINS, 2017), levou à perda de cerca de 900 hectares, o que inutilizou $95 \%$ das terras férteis da reserva (FLORIT et al, 2016). Hoje, existe uma disputa judicial para ampliar a área para 37 mil hectares, seguindo a proposta realizada pela FUNAI em 1994 (CAMARGO, 2015). Mesmo após uma série de protestos e conflitos, a ampliação ainda não foi realizada.

Fernandes e Piovezana (2015) lembram ainda dos conflitos entre Kaingang e agricultores, enquanto Darella (2003), Neira et al (2009) e Caderno SPI (2018) relatam conflitos envolvendo os Guarani. A FIOCRUZ (sem data) detalha outros conflitos, como aqueles relacionados ao acesso ao território, à degradação ambiental, mas também outros relativos à especulação imobiliária, a obras públicas em territórios tradicionais, à degradação ambiental.

Assim como os povos indígenas, as Comunidades Quilombolas têm na constituição garantidos os direitos aos territórios. Embora tanto sua cultura como as situações de conflitos guardem suas especificidades, também enfrentam situações semelhantes aos povos indígenas.

Com efeito, o Decreto $n^{\circ} 4.887$, de 20 de novembro de 2003, em seu artigo $2^{\circ}$, define as Comunidades Quilombolas como "grupos étnico-raciais, segundo critérios de autoatribuição, com trajetória histórica própria, dotados de relações territoriais específicas, com presunção de ancestralidade negra relacionada com a resistência à opressão histórica sofrida" (BRASIL, 2003).

Segundo a Secretaria de Políticas de Promoção da Igualdade Racial da Presidência da República (2014), existem 17 comunidades quilombolas em Santa Catarina (COMISSÃO PRÓ-ÍNDIO DE SÃO PAULO, sem data). Destas, apenas três estão demarcadas: Família Thomaz, em Treze de Maio; São Roque, em Praia Grande; e Invernada dos Negros, localizada entre os municípios de Campos Novos e Abdon Batista.

Diferentes autores indicam a existência de conflitos na luta pelo reconhecimento dos territórios quilombolas em Santa Catarina (FERNANDES et al, 2006; LEITE, 2010; MOMBELLI, 2015). Em geral, os conflitos envolvem o reconhecimento e titulação de suas terras e afetam a manutenção dos modos de vida.

Os Pescadores Artesanais são definidos pelo Decreto $\mathrm{n}^{\circ} \mathbf{8 . 4 2 5}$, de 31 de março de 2015 como sendo aqueles que exercem "a pesca com fins comerciais de forma autônoma ou em regime de economia familiar [...] podendo atuar de forma desembarcada ou utilizar embarcação de pesca com arqueação bruta menor ou igual a vinte" (Brasil, 2015). No âmbito acadêmico, a pesca artesanal vem sendo caracterizada pela produção de baixa escala, pela utilização de barcos de até 15 metros e exercida por tripulação reduzida. Ainda assim, a produção da pesca 
artesanal representa a maior parte do pescado consumido no Brasil (KNOX; TRIGUEIRO, 2015, p. 22) $)^{3}$.

Relatadas pelo Conselho Pastoral da Pesca (CPP) (2016), os principais conflitos envolvendo pescadores artesanais e diferentes atividades em Santa Catarina são: pesca industrial, conflitos com surfistas, especulação imobiliária, turismo predatório, privatização de terras públicas, carcinicultura e o cultivo de arroz industrial. O relatório da CPP chama a atenção para a criação de reservas extrativistas que tendem a colocar em risco o território dos pescadores. A FIOCRUZ (2010) indica a construção de hidrelétricas como potencial gerador de conflitos, o que foi corroborado por Bittencout (2018). A maioria dos conflitos mencionados nestes relatórios ocorrem no litoral marítimo, mas também podem ocorrer no interior.

Também ligados à pesca, os Açorianos são descendentes de imigrantes do Arquipélago dos Açores que migraram para diversas partes do mundo. Em Santa Catarina, os primeiros açorianos chegaram entre os anos 1748 e 1756 (CAMPOS, 1989; LACERDA, 2003). Conforme Campos (1989), as características da formação social açoriana no litoral catarinense era pequena produção mercantil baseada nas terras de uso comum, herança da antiga estrutura da comunidade agrária portuguesa. As terras de uso comum teriam desaparecido por influência do Estado, que levou a pequena produção à subordinação aos interesses capitalistas e modificado os traços culturais dessa população.

Vivendo principalmente na faixa litorânea de SC, na atualidade, a população de origem açoriana sofre ainda com o impacto da expansão urbana e demográfica, a balnearização dos antigos núcleos povoadores e o crescimento do turismo (LACERDA, 2003). Esses fatores acarretaram mudanças significativas em seus modos de vida.

Nesse contexto, considerando a dimensão populacional e sua distribuição geográfica e a ausência de muitas das características apresentadas anteriormente (pequena produção, terras de uso comum), há uma dificuldade em classificá-los como comunidade tradicional no sentido estrito. Entretanto, seu histórico permite vê-los como comunidade tradicional que teria se desagregado justamente em função dos conflitos envolvendo seus territórios e modo de vida (CAMPOS, 1989; LACERDA, 2003).

A origem da Comunidade Cafuza em Santa Catarina está profundamente ligada à Guerra do Contestado. Ocorrida entre os anos 1912 e 1916 no norte de SC e sul do PR, foi marcada pela usurpação das terras dos caboclos da região pelo Estado e sua entrega à ferrovia Brazil Railway Company e à madeireira e colonizadora internacional Southern Brazil Lumber and Colonization Company (ABREU, 2015). Os cafuzos são descendentes desses caboclos que saíram derrotados na guerra. Ao final dela, vagaram pelo planalto catarinense, passando pela Serra Geral e se fixando na Serra do Mirador. Em 1947, foram "assentados" na Terra Indígena de Ibirama já mencionada, em José Boiteux (distrito de Ibirama até 1989), fundando a Comunidade Cafuza (MARTINS, 1991).

\footnotetext{
${ }^{3}$ Para uma discussão mais aprofundada sobre o conceito de pesca artesanal ver ANDRIGUETTO FILHO, 1999, pp. 12-18)
} 
Chamada de Cafuzeiro, a sede da comunidade estava localizada no Vale do Rio Platê. Porém, Athayde e Martins (2017) observam que, com a implantação da Barragem Norte, já referida, perderam cerca de um terço dos mil hectares de terra que detinham. Consequentemente, passaram a disputar espaço com os XoklengLaklãnõ. Como estes tinham primazia na escolha os Cafuzos tiveram que deixar a área.

Atualmente, os Cafuzos estão assentados na localidade do Alto Rio Laeisz, em José Boiteux (ATHAYDE; MARTINS, 2017). Segundo Kummrow (2013), o assentamento abriga cerca de 40 famílias, aproximadamente 120 pessoas. $O$ número é inferior às 100 famílias que já ocuparam o lugar. A autora traz o relato do do senhor Antônio Siqueira, habitante do lugar, quem afirma que as famílias se evadiram por conta das más condições do local. De acordo com Kummrow (2013), a comunidade está localizada em uma serra alta e de difícil acesso. As terras foram garantidas através da Reforma Agrária há mais de 20 anos (ATHAYDE; MARTINS, 2017). Embora a história desta comunidade seja marcada pelo conflito envolvendo suas terras, atualmente vivem em relativa paz.

Ao longo de muitas gerações, desde o início do século XX e com práticas que remontam aos índios Carijós, os Cipozeiros vivem da extração de diferentes espécies de cipó (sendo o imbé o principal), que são vendidos em estado bruto ou utilizados para a confecção de diversos tipos de artesanatos. Eventualmente, complementam a renda com outras atividades, como a extração de outros recursos florestais e o trabalho assalariado (ANTUNES, 2011).

Descendentes de europeus e indígenas vivem no norte de Santa Catarina e no sul do Paraná. No Brasil, há cerca de 10 mil pessoas que se identificam como cipozeiros. Em Santa Catarina, estão localizados nos municípios de Garuva, Joinville, Araquari e Itapoá. Garuva é o município que concentra a maior parte dessa população, mais de 200 famílias (ALMEIDA, et al, 2007; BUSTAMANTE, et al, 2015; ANTUNES, 2011; GRAVA; FLORIT; ANTUNES, 2019).

Os Cipozeiros vêm enfrentando muitos obstáculos para a manutenção de seu modo de vida. Esses obstáculos são restrições jurídicas, ambientais, sociais, econômicas. As áreas em que realizam a extração vêm diminuindo gradativamente. Em geral, os locais de extração eram terras devolutas que têm se tornado áreas particulares, propriedade de grandes empresas que nem sempre permitem 0 acesso. $O$ desmatamento e a substituição de áreas de floresta por monoculturas de pinus, eucalipto, arroz, banana e pastagens também vêm reduzindo seu território. Nas áreas em que ainda restam as árvores em que o cipó é encontrado, é requerida a permissão de acesso (em alguns casos mediante o pagamento de taxas), ou acabam assumindo o risco de invadir as propriedades, podendo enfrentar até mesmo conflitos armados (ALMEIDA et al, 2007).

Verifica-se, entre as cipozeiras e cipozeiros, que existe uma preocupação com a regeneração dos recursos, existindo uma série de interdições e regras relativas ao uso da natureza. Isso significa que o uso dos recursos naturais não é meramente instrumental. Esta afirmação passa por reconhecer os aspectos identitários e de coesão social nesse modo de vida. Também, passa pela constatação do papel reconhecido à regeneração do recurso que existe na natureza, cujo uso não se associa à propriedade da terra, mas a um bem comum. Neste sentido, o bem comum conecta o recurso a uma trama de valoração muito 
complexa, ancestral e comunitária, carregada de aspectos simbólicos indissociáveis da utilidade instrumental dele.

As trocas comerciais são realizadas para suprir uma série de necessidades, para comprar aquilo que não podem produzir. Essas trocas eram muito menos frequentes "no tempo dos antigos", quando o acesso aos territórios era facilitado e havia maior disponibilidade de recursos naturais e matéria-prima (ANTUNES, 2011).

Destaca-se a importância e a centralidade do cipó para o modo de vida cipozeiro. Ainda que sejam pluriativos ${ }^{4}$, dedicando-se à agricultura, à criação de animais, à pesca, atividades que servem de subsistência e para troca (escambo), sua principal fonte de renda monetária vem da venda do artesanato do cipó. Ademais, sua identidade tem o cipó como espinha dorsal, reconhecendo-se, antes de tudo, como "Cipozeiras" e "Cipozeiros".

Entre 2009 e 2010, Antunes (2011) mapeou os principais conflitos em cada comunidade segundo o relato dos próprios Cipozeiros. Entre eles estão: fiscalização ambiental; falta de matéria-prima; preço baixo/injusto; distância para se chegar ao recurso; acesso restrito, repressão ilegal por "jagunços"; desmatamento; grilagem/golpes/expulsão; especulação imobiliária; monoculturas; falta de compradores; exploração da mão-de-obra por parte de atravessadores.

Nesse contexto, os grupos têm se organizado em movimentos e redes para lutar pela garantia de acesso aos territórios e pela manutenção de seus modos de vida. Atualmente, fazem parte do Conselho Nacional dos Povos e Comunidades Tradicionais [CNPCT], instituído pelo Decreto $\mathrm{N}^{\circ}$ 8.750, de 9 de maio de 2016 (BRASIL, 2016), que garante aos cipozeiros direito à representação. No âmbito local, a Lei Municipal $n^{0}$ 1981, de 28 de abril de 2017, em processo de implementação, reconhece, inclusive através de certificação, a existência social dos grupos denominados Povos e Comunidades Tradicionais no município de Garuva (GARUVA, 2017).

Os Faxinalenses são, agricultores que desenvolveram um sistema próprio de produção chamado Faxinal. O sistema se baseia, essencialmente: 1) na criação extensiva de animais soltos em áreas comuns - as terras de criar; 2) na extração de erva-mate e madeira; e 3) na policultura alimentar nas chamadas terras de plantar circunvizinhas. Além da distinção entre as terras de criar e as terras de plantar, o sistema de cercas, as matas mistas com ervais nativos como condicionante físiconatural, as relações de compadrio e mutirão e a medicina e religiosidade popular são características peculiares desse sistema e cultura, que propicia economia de recursos e mantém reunida a mão de obra necessária para a execução das atividades (CHANG, 1985; FÖETSCH, 2014).

Para alguns autores, o sistema estaria em desagregação em Santa Catarina, sobretudo por conta de restrições da legislação ambiental e da intensificação e "tecnificação" da produção agropecuária, aumentando a competição com a grande produção (CHANG, 1985; MELLO; PERONI, 2015). Föetsch (2014) indica que a desagregação dos faxinais teria resultado nas Caívas, que, de forma análoga aos Faxinais, seria uma forma de organização social, de territorialidade e de aproveitamento dos recursos naturais.

\footnotetext{
${ }^{4}$ Adotamos a expressão de Schneider (2003).
} 
Föetsch e Schwarzer (2016) observam que algumas comunidades de municípios catarinenses mantiveram elementos característicos do sistema de faxinal, como as matas mistas com ervais nativos e a presença do caboclo e do imigrante. Mello e Peroni (2015) afirmam que, hoje, não existem faxinais em Santa Catarina, mas que as Caívas teriam similaridades históricas e de práticas de manejo dos recursos naturais, existindo comunidades remanescente de Faxinais em Três Barras, Irineópolis, Major Vieira e Canoinhas.

A desagregação do modo de vida faxinalense e o surgimento das Caívas abrem uma nova discussão. Ainda que não apresentem todas as características, as Caívas guardam vários aspectos que permitem entendê-los como comunidades tradicionais. A própria situação de conflito seria a causa da desagregação que levou à adaptação a uma nova realidade.

Os Povos Pomeranos são descendentes dos habitantes da antiga Pomerânia, região localizada entre o norte da Polônia e da Alemanha e que pertenceu ao Sacro Império Romano-Germânico até o começo do século XIX. Posteriormente, a Pomerânia fez parte da Prússia e, terminada a Segunda Guerra Mundial, foi finalmente dividida entre Polônia e Alemanha (CAMPOS, 2015).

Buscando melhores condições de vida, os Pomeranos migraram para diversas partes do mundo, principalmente no Brasil, no Canadá e nos Estados Unidos (CAMPOS, 2015). Em Santa Catarina, chegaram a partir de 1861, estabelecendo-se no Vale do Itajaí, principalmente em Pomerode (BERNDT, 2018).

O pesquisador Moyses Berndt (2018), em entrevista cedida aos autores, com questões abertas e por meio de correio eletrônico, informou que existem alguns obstáculos para a compreensão dos Povos Pomeranos em Santa Catarina. Ele cita a miscigenação com alemães de outras procedências, sendo que até os anos 1940, havia apenas escolas Luteranas, o que levou ao confinamento do idioma Plattdeutsch ao âmbito familiar. Esse confinamento teria se acentuado com a perseguição sofrida durante o período do Estado Novo, em 1940. Assim, a identidade e as práticas ligadas ao Povo Pomerano perderam força em SC e, consequentemente, com sua diluição, não há dados disponíveis sobre este grupo.

Consequentemente, não é possível afirmar que o Povo Pomerano em Santa Catarina perdure enquanto comunidade tradicional, nos termos definidos pelo Decreto $n^{\circ} 6.040 / 2007$. Contudo, considerando sua história e a realidade vivida em outros estados, como Espírito Santo, é possível que ao menos algumas comunidades guardem características semelhantes, como o uso da língua Plattdeutsch, a religião e o modo de produção artesanal.

Os Povos e Comunidades Tradicionais em Santa Catarina estão distribuídos conforme o mapa abaixo: 
Mapa 1. Povos e Comunidades Tradicionais em Santa Catarina - localização por município

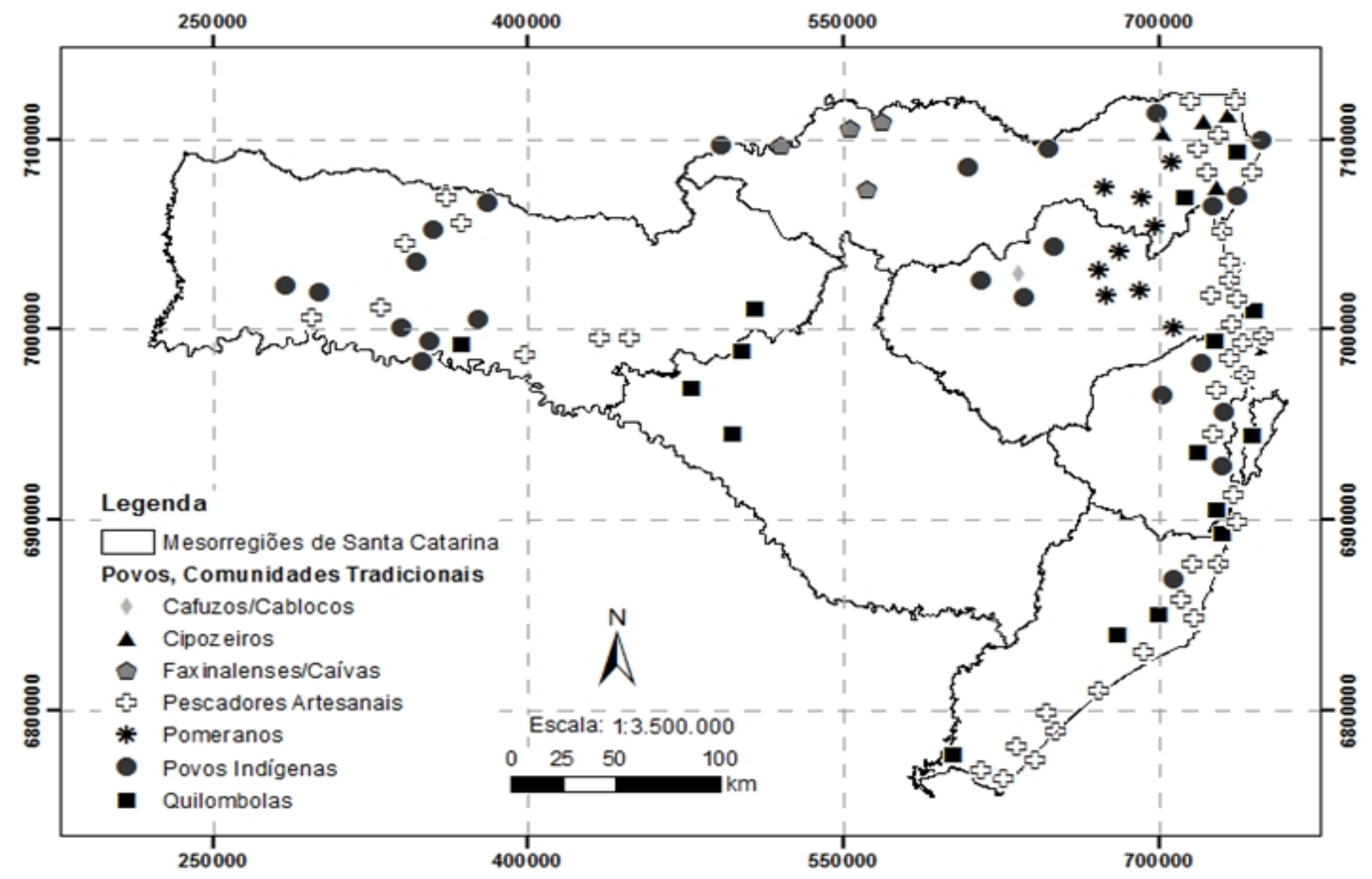

Fonte: Elaborado por Patrícia Scaburri (2018) do LABGEO-FURB 5 .

\section{0 prisma da Ecologia Política e da Justiça Ambiental}

O processo de reprimarização da economia impulsionou à expansão da fronteira agropecuária e energética, levando agentes públicos e privados a novas incursões sobre os territórios de povos e comunidades tradicionais. Nesse sentido, as perspectivas da Ecologia Política e da Justiça Ambiental prestam contribuição decisiva para o entendimento da realidade catarinense (MARTINS, 2009; NEGRI; ALVARENGA, 2011; CANO, 2012; NASSIF, 2012; CEPAL, 2012; GUDYNAS, 2012; SVAMPA, 2013).

Martínez-Alier (2006) observa que o termo ecologia política foi usado pela primeira vez em 1957, por Bertrand de Jouvenel, mas foi popularizado pelo antropólogo Eric Wolf, em 1972. No entanto, foi somente nos anos 1980 que a Ecologia Política emergiu como o estudo dos conflitos ecológicos distributivos (sobre recursos ou serviços ambientais), consequência das crises [socio]ambientais,

\footnotetext{
${ }^{5}$ Produzido para o artigo a partir de dados informados pelos autores.
} 
ou crise ambiental, após a Segunda Guerra Mundial (LIPIETZ, 2002) e de estudos de caso da Geografia e da Antropologia rurais (MARTíNEZ-ALIER, 2006).

Porto-Gonçalves destaca que a discussão sobre a dimensão política no debate sobre a natureza ganhou força com as publicações de:

[...] Primavera Silenciosa (1962), de Rachel Carson, Population Bomb (1968), de Paul Erlich, da Estratégia do Desperdício de Vance Packard (1965), do The Economic Process and the Entropy Law de Nicholas Georgescu Roegen (1971), do The Limits to Growth de Meadows e Meadows (1972), do Para una crítica de la ecologia política, de Hans Magnus Enzensberg (1973), [e] O Mito do Desenvolvimento de Celso Furtado (1974) (PORTO-GONÇALVES, 2012, p. 19, grifos originais).

Ademais, com a conferência mundial sobre o meio ambiente, em Estocolmo, no ano de 1972, a questão ambiental entrou na agenda geopolítica internacional.

Partindo de uma crítica aos fundamentos ontológicos e metafísicos da epistemologia moderna (positivismo, estrutural-funcionalismo), Porto-Gonçalves (2012) e Leff (2003) afirmam que a Ecologia Política não é só um campo de estudo, mas também de ação política. Além dos conflitos ecológicos distributivos, preocupa-se com as relações de poder que se estabelecem entre o mundo da vida das pessoas e o mundo globalizado. Congrega contribuições de diversos campos de estudo, como economia ecológica, direito ambiental, sociologia política, antropologia das relações cultura-natureza, ética política (LEFF, 2003).

Segundo Leff, a Ecologia Política surge do entorno da economia ecológica para analisar os processos de significação, valoração e apropriação da natureza que não se resolvem nem pela monetarização da natureza, nem pela aplicação de normas ecológicas à economia. De modo geral, foca-se no problema da "distribuição ecológica", de modo a compreender as externalidades ambientais e os movimentos sociais que surgem dos "conflitos distributivos" [ecológicos] (LEFF, 2003, p. 19).

Conforme Leff:

[...] a distribuição ecológica aponta em direção a processos de valorização que vão além da racionalidade econômica em suas tentativas de atribuir preços de mercado e custos crematísticos ao meio ambiente, mobilizando atores sociais por interesses materiais e simbólicos (de sobrevivência, identidade, autonomia e qualidade de vida), além das exigências estritamente econômicas de propriedade dos meios de produção, de emprego, de distribuição de renda e de desenvolvimento (LEFF, 2003, p. 20, tradução nossa).

Nesse sentido, a Ecologia Política estabelece uma relação íntima com a perspectiva da Justiça Ambiental, ambas questionando a distribuição desigual do acesso aos recursos ambientais e das externalidades que decorrem deste uso, bem como a racionalidade e os mecanismos que operam esta distribuição desigual.

A perspectiva da Justiça Ambiental reúne um ponto de vista ético-político e uma base epistemológica. O primeiro ponto deriva de sua definição precisa de "injustiça ambiental" como sendo aquela que impõe danos ambientais desproporcionais a grupos sociais específicos em função de sua posição 
subordinada. Sua base epistemológica, o segundo ponto, provém da afirmação que as divisões sociais predefinem a lógica de distribuição desigual desses impactos e a exposição desigual a ambientes insalubres, degradados ou de risco. Dessa perspectiva resulta um novo vigor para a crítica social inerente à discussão ambiental, que sempre esteve presente na agenda ambientalista, mas que teria perdido espaço para outras abordagens.

Autores como Acselrad (2000), Bullard (2010), Figueroa e Mills (2001) e Hartley (2003) apontam que o Movimento por Justiça Ambiental [Environmental Justice Movement] se constituiu nos EUA, nos anos 1980, sendo resultado da articulação entre lutas de caráter social, territorial, ambiental e de direitos civis. Herculano define justiça ambiental como:

[...] o conjunto de princípios que asseguram que nenhum grupo de pessoas, sejam grupos étnicos, raciais ou de classe, suporte uma parcela desproporcional das consequências ambientais negativas de operações econômicas, de políticas e programas federais, estaduais e locais, bem como resultantes da ausência ou omissão de tais políticas (HERCULANO, 2002, p. 2).

A injustiça ambiental seria um mecanismo perverso no qual sociedades desiguais distribuem desproporcionalmente as maiores cargas de danos ambientais, resultado de processos de desenvolvimento, a grupos mais vulneráveis, como trabalhadores, pobres, grupos raciais discriminados e outras populações marginalizadas (HERCULANO, 2002). A injustiça ambiental também ocorre quando estes mecanismos propiciam uma apropriação desigual e desproporcional dos recursos do território, despojando povos e comunidades que não estão inseridos na lógica da economia urbano-industrial.

Dessa forma, tanto a Ecologia Política como a Justiça Ambiental revelam que a racionalidade instrumental moderna impõe uma forma de dominação sobre o mundo natural e sobre grupos sociais específicos sobre os quais operam formas de opressão, de classe, gênero, etnia, raça, que se combinam de forma interseccional ${ }^{6}$. Trata-se de lógicas distintas de apropriação social do mundo natural que se contrapõem com a racionalidade instrumental mercadológica, e abrigam racionalidades ambientais que, embora venham sendo dramaticamente ameaçadas, possuem formas de uso e valoração do mundo natural que são preciosas ao se pensar o desenvolvimento sustentável a partir de abordagens plurais (LEFF, 2004; ACSELRAD, 2008; PORTO-GONÇALVES; LEFF, 2015; GUDYNAS, 2004).

Por outro lado, em que pese a relevância social desses grupos, os três elementos que sintetizam sua condição - a economia identitária e não crematística, a despossessão territorial e a opressão interseccional - são causa de invisibilidade estrutural, e a consequente ausência de dados sistematizados abrangentes sobre eles. Por isso, um dos desafios é o de trabalhar com dados que muitas vezes são inconsistentes e, em alguns casos, divergentes (como números referentes à população indígena ou cipozeira, dados socioeconômicos referentes a cada comunidade, dentre outros).

\footnotetext{
${ }^{6}$ Sobre o tema da interseccionalidade, ver, dentre outros, Bueno (2017) e Crenshaw (2017).
} 
Desse modo, por um lado, torna-se difícil não somente a caracterização e a produção de conhecimento sobre as populações tradicionais em Santa Catarina, mas também a formulação de políticas públicas que atendam especificamente e de modo satisfatório as necessidades dessas populações. Por outro lado, essa constatação mostra a urgência e a relevância em se produzir dados quantitativos e qualitativos sobre estas comunidades.

Os estudos dos campos da Ecologia Política e da Justiça Ambiental vêm demonstrando a existência de uma correlação entre raça, classe e etnia e uma distribuição desigual do acesso aos recursos naturais e dos danos derivados do uso desses recursos. Nesse sentido, nosso levantamento corrobora as teses desses campos, mostrando que as populações tradicionais em Santa Catarina frequentemente enfrentam situações de injustiça ambiental. Seus territórios tradicionais têm sido alvo da especulação imobiliária, do turismo predatório, da monocultura, do desmatamento, da restrição de acesso aos territórios, dentre várias outras situações. As comunidades propriamente ditas, vítimas de racismo e diversas formas de menosprezo.

\section{Conflitos Ambientais Territoriais e de Valoração}

Os conflitos ambientais mostram que existem diferentes formas de valoração da natureza. As racionalidades das populações tradicionais, com formas particulares de valoração da natureza, encontram-se, em sua grande maioria, ameaçadas pela racionalidade instrumental e homogeneizadora do espaço do capitalismo globalizado. Esta racionalidade "moderna" compreende os territórios tradicionais unicamente como fornecedores de matéria-prima, alimentos e energia. Os modos de vida e as territorialidades de comunidades ancestrais são totalmente ignorados pela lógica de mercado. Os conflitos, portanto, expressam-se principalmente através da dimensão territorial (FLORIT, 2016; 2019; GRAVA, 2017).

A maioria das populações tradicionais são pluriativas. Conciliam várias formas de produção agrícola, extrativismo, caça, pesca, e são apenas parcialmente integrados ao mercado. Possuem vínculo forte com os lugares onde vivem, aos quais se associam formas específicas de uso do território e de seus recursos naturais. Estes usos se conformam aos ciclos naturais e são regulados por regras comunitárias. Essas dinâmicas resultam em modos de produção do espaço e da vida intimamente vinculados à natureza (FLORIT, 2019).

As experiências vivenciadas por povos e comunidades tradicionais em Santa Catarina podem ser consideradas como situações de conflitos ambientais territoriais. Para Laschefski (2011), os conflitos ambientais são resultado da expansão do espaço ambiental de grupos privilegiados. Segundo este autor, os conflitos podem ser classificados de três formas: espaciais, distributivos e territoriais ${ }^{7}$.

Os conflitos ambientais espaciais ocorrem nos casos de poluição que afetam a qualidade de vida da população atingida. Podem ser resolvidos através de meios técnicos (como filtros, por exemplo) na medida em que algum dispositivo consiga

\footnotetext{
${ }^{7}$ Sobre o tema, ver também Zhouri e Laschefski (2010).
} 
limitar ao território do próprio gerador o impacto da poluição. Neste caso, a territorialidade do gerador não compromete a territorialidade do atingido.

Os conflitos ambientais distributivos são os que revelam assimetrias nos benefícios decorrentes da apropriação e uso dos recursos e serviços ambientais. A estes cabem apenas um tratamento através de perspectivas ambientalizadas de economia política ou da ecologia política.

Já nos conflitos ambientais territoriais ocorre a sobreposição da territorialidade de grupos mais poderosos sobre territórios de grupos subalternizados, como nos casos de muitas das populações tradicionais, sem que sejam oferecidas condições de reproduzir suas relações socioambientais. Neste tipo de conflitos:

[...] as territorialidades de grupos sociais, ou seja, os modos diferenciados de apropriação simbólica e material do meio ambiente, envolvem justamente modos distintos de ver o mundo ou de "produzir" o espaço que, quando materializados no espaço concreto, se revelam incompatíveis (LASCHEFSKI, 2011, p. 29).

Portanto, trata-se do resultado de relações de poder desiguais entre os que promovem o modo urbano-industrial-capitalista de produção do espaço e as comunidades locais.

Os conflitos territoriais evidenciam territorialidades de grupos contrapostos, as quais envolvem valorações da natureza também conflitantes. No caso da territorialidade das comunidades tradicionais, essas valorações permitem lógicas de uso específicas que são diferentes da lógica capitalista moderna, que tem como métrica de valoração o parâmetro monetário e que, por sua integração à economia de mercado, tende a subestimar os atributos que não são coisificáveis.

Segundo Martínez-Alier, "[...] existe um choque de sistemas de valoração quando os discursos da justiça ambiental, dos direitos territoriais indígenas ou da segurança ambiental se desdobram em oposição à valoração monetária dos riscos e das cargas ambientais" (MARTíNEZ-ALIER, 2007, p. 353).

Conforme Florit, isso ocorre porque:

[...] a atribuição de valor monetário, procedimento operacional de valoração no qual todos os valores são reduzidos a uma única escala, só é possível na medida em que algumas qualidades dos entes valorados são consideradas importantes e outras são desconsideradas (Florit, 2016, p. 265).

No caso dos povos e comunidades tradicionais em Santa Catarina, sua produção do espaço, embora contenham uma valoração de uso da natureza na medida em que dependem do uso direto desta para atender suas necessidades vitais, implica em uma combinação complexa de valorações, não apenas instrumentais, que adicionam uma carga de sentido e significação simbólica que é indissociável do uso para o provimento material.

Reconhecer essa carga de sentidos e valorações ajuda a entender por que há algo que esses povos defendem que não é substituível através de operações monetarizadas, que embora esteja conectado com seu suprimento material não se 
reduz a ele. Isso indica que seu uso da natureza, do rio, dos animais, não é apenas o uso de um ambiente produtivo, mas também a defesa de algo ao que se reconhece consideração moral, que não é traduzível em termos monetários.

\section{Considerações Finais}

As perspectivas da Ecologia Política e da Justiça Ambiental pontuam que as clivagens sociais predefinem a lógica de distribuição desigual do acesso aos recursos naturais e dos impactos decorrentes de seu uso. Nesse sentido, o trabalho mostra que os povos e comunidades tradicionais em Santa Catarina enfrentam, em sua grande maioria, algum tipo de conflito ambiental territorial. Esses conflitos territoriais, por sua vez, muitas vezes se intereseccionam com outras formas de discriminação.

Considerando que essas populações dependem diretamente da exploração dos recursos naturais disponíveis em seus territórios para a manutenção de sua vida material e cultural, a situação de conflito ambiental territorial ameaça diretamente seus modos de vida, conformando-se, assim, como situação de injustiça ambiental.

Por meio do levantamento de pesquisas já realizadas por diversos pesquisadores, verificamos que todos os grupos já sofreram ou ainda sofrem alguma situação de conflito envolvendo seus territórios. Esses conflitos estão relacionados com garantia de ocupação da terra, com limitação de acesso aos recursos, com ameaças de violência física, com a fiscalização ambiental que ignora os modos de vida, mesmo no caso de uso conservacionista da natureza por parte desses grupos.

A dificuldade de encontrar dados, e as inconsistências entre eles, também indica que essas populações estão invisibilizadas. Isso torna ainda mais difícil a caracterização e a produção de conhecimento sobre as populações tradicionais em SC, e a formulação de políticas públicas que atendam especificamente e de modo satisfatório as necessidades das mesmas.

Contudo, considerando as informações reunidas, é possível corroborar que a tese da Justiça Ambiental, de que as divisões sociais predefinem a lógica de distribuição desigual do acesso aos recursos naturais e dos impactos decorrentes de seu uso, aplica-se à situação dos povos e comunidades tradicionais em SC. Também, verificamos que há, entre os povos e comunidades tradicionais, uma valoração da natureza que não se baseia tão somente em sua valoração monetária ou instrumental. Isso permite formular, conforme conceitos da Ecologia Política, a hipótese da existência de formas de organização econômica não crematísticas que combinam a produção de bens de uso com a consideração moral da natureza.

De fato, os povos e comunidades tradicionais, em SC, parecem manter valorações da natureza diferenciadas que colocam limites morais ao uso predatório dos recursos. Suas lutas territoriais se apoiariam em ontologias distintas, não dualistas, das quais surgem valorações incomensuráveis do ponto de vista da sociedade envolvente, o que, por sua vez, contribui para sua invisibilidade estrutural. É necessário conhecer essas concepções e as valorações associadas e, para isso, reconhecer e garantir seus direitos territoriais. Por isso é fundamental apreciar melhor, e com especificidade territorial, as lógicas e demandas desses povos. Esse será um passo fundamental para reconhecê-los como sujeitos genuínos 
do desenvolvimento territorial, e assim inclui-los para participar da formulação de políticas públicas que os atendam.

\section{REFERÊNCIAS}

ABREU, Alzina Alves (coord.). Dicionário Histórico-Biográfico da Primeira República: 1889-1930. Rio de Janeiro: FGV, 2015.

ACSELRAD, Henri. Justiça Ambiental - novas articulações entre meio ambiente e democracia. In: IBASE/CUTRJ/IPPUR-UFRJ. Movimento Sindical e Defesa do Meio Ambiente - o debate internacional. Rio de Janeiro: Série Sindicalismo e Justiça Ambiental, vol. 3, 2000, pp.7-12.

ACSELRAD, Henri. Sustentabilidade e articulação territorial do desenvolvimento brasileiro. Santa Cruz do Sul: II Seminário Internacional sobre Desenvolvimento Regional, 2008, pp. 1-47. Disponível em: <http://www.ettern.ippur.ufrj.br/publicacoes/68/sustentabilidade-e-articulacaoterritorial-do-desenvolvimento-brasileiro>. Acesso em: 24/11/2016.

ALMEIDA, Alfredo Wagner Berno de; MARIN, Rosa E. Acevedo; NETO, Joaquim Shiraishi (coordenadores). Cipozeiros de Garuva: Floresta Atlântica, Santa Catarina. Florianópolis: Projeto Nova Cartografia Social dos Povos e Comunidades Tradicionais do Brasil, fascículo 9, março de 2007.

ANDRIGUETTO FILHO, José Milton. Sistemas técnicos de pesca e suas dinâmicas de transformação no litoral do Paraná, Brasil. 1999. 242f. Tese (Doutorado em Meio Ambiente e Desenvolvimento) - Programa de Pós-Graduação em Meio Ambiente e Desenvolvimento, Universidade Federal do Paraná, Curitiba, 1999.

ANTUNES, Douglas Ladik. Cipozeiros em Movimento: cultura material, conflitos territoriais e relações educativas em design. Tese (Doutorado em Design), Pontifícia Universidade Católica do Rio de Janeiro, Rio de Janeiro, 2011.

ATHAYDE, Marcia Fusinato Barbosa; MARTINS, Pedro. Barragem Norte e suas influências socioespaciais no Município de José Boiteux - SC: um olhar sobre as comunidades atingidas. Florianópolis: Geosul, v. 32, n. 64, maio/ago. 2017, pp. 110125. Disponível em: <https://periodicos.ufsc.br/index.php/geosul/article/view/21775230.2017v32n64p110>. Acesso em: 31/01/2018.

BITTENCOURT, Ana Lúcia. Conflitos socioambientais em torno da água em Santa Catarina: desenvolvimento regional e atuação estatal. 2018. $251 \mathrm{f}$, il Tese (doutorado) - Universidade Regional de Blumenau, Centro de Ciências Humanas e da Comunicação, Programa de Pós-Graduação em Desenvolvimento Regional 2018.

BERNDT, Moyses. Informações sobre a Comunidade Pomerana em SC [mensagem pessoal]. Mensagem recebida por <diego.grava@gmail.com> em 22/02/2018. 
BRANDÃO, Carlos Rodrigues. A comunidade tradicional. In: UDRY, Consolación; EIDT, Jane Somini (editoras técnicas). Conhecimento Tradicional: Conceitos e Marco Legal. Brasília: Embrapa. Coleção Povos e Comunidades Tradicionais, 2015, pp. 21-101.

BRASIL. Constituição da República Federativa do Brasil. Brasília: Presidência da República [online], 1988. Disponível em: <http://www.planalto.gov.br/ccivil_03/constituicao/constituicaocompilado.htm>. Acesso em: 25/08/2017.

BRASIL. Decreto № 4.887, de 20 de novembro de 2003. Brasília: Presidência da República [online], 20/11/2003. Disponível em:

<http://www.planalto.gov.br/ccivil_03/decreto/2003/d4887.htm>. Acesso em: 01/12/2017.

BRASIL. Decreto $n^{\circ}$ 6.040, de 7 de fevereiro de 2007. Brasília: Presidência da República [online], 07/02/2007. Disponível em:

<http://www.planalto.gov.br/ccivil_03/_at02007-2010/2007/decreto/d6040.htm>. Acesso em: 25/05/2017.

BRASIL. Decreto $n^{\circ}$ 8.425, de 31 de março de 2015. Brasília: Presidência da República [online], 31/03/2015. Disponível em: <http://www.planalto.gov.br/ccivil_03/_ato20152018/2015/decreto/d8425.htm>. Acesso em: 10/04/2018.

BRASIL. Decreto n 8.750, de 9 de maio de 2016: Institui o Conselho Nacional dos Povos e Comunidades Tradicionais. Brasília: Presidência da República [online], 09/05/2016. Disponível em: <http://www.planalto.gov.br/ccivil_03/_At020152018/2016/Decreto/D8750.htm\#art20 >. Acesso em: 24/08/2017.

BUENO, Winnie. Umas poucas linhas sobre racismo ambiental. Justificando, 23/11/2017. Disponível em: <http://www.justificando.com/2017/11/23/umas-poucaslinhas-sobre-racismo-ambiental/>. Acesso em: 30/04/2020.

BUSTAMANTE, Ana Maria Goulart; CABRAL, Diogo de Carvalho; SILVA, Jorge Kleber Teixeira. Patrimônio ambiental e diversidade Cultural do Brasil. In: UDRY, Consolación; EIDT, Jane Somini (editoras técnicas). Conhecimento Tradicional: conceitos e marco legal. Brasília: EMBRAPA. Coleção Povos e Comunidades Tradicionais, 2015, pp. 103-159.

CADERNO SPI. Terra Indígena Pindoty: Os Guarani Mbya e a luta pela demarcação. Youtube [online], 15/04/2018. Disponível em:

<https://www.youtube.com/watch?v=t3ylJJyG1Rc\&feature=youtu.be $>$. Acessado em: 17/04/2018.

CAMARGO, Aline. Demora do processo de expansão da Reserva Duque de Caxias motivou a tomada da Barragem Norte. Jornal NSC Total (Clic RBS) [online], 
18/04/2015. Disponível em:

<http://jornaldesantacatarina.clicrbs.com.br/sc/geral/noticia/2015/04/demora-doprocesso-de-expansao-da-reserva-duque-de-caxias-motivou-a-tomada-da-barragemnorte-4742719.html> Acesso em: 09/01/2018.

CAMPOS, Gustavo Barreto de. Dois séculos de imigração no Brasil: A construção da imagem e papel social dos estrangeiros pela imprensa entre 1808 e 2015. Rio de Janeiro, 2015. Tese (Doutorado em Comunicação e Cultura) - Escola de Comunicação, Universidade Federal do Rio de Janeiro, Rio de Janeiro, 2015.

CAMPOS, Nazareno José de. Terras Comunais e Pequena Produção Açoriana na Ilha de Santa Catarina. Dissertação (Mestrado em Geografia), Universidade Federal de Santa Catarina, Florianópolis, 1989. Disponível em:

<https://repositorio.ufsc.br/handle/123456789/111479> Acesso em: 07/02/2018.

CANO, Wilson. Industrialização, desindustrialização e políticas de desenvolvimento. Bauru: Revista Faac, v. 1, n. 2, out.2011/mar.2012, p. 155-164.

CHANG, Man Yu. Faxinais no Paraná. Londrina: Geografia, v. 3, n. 3, 1985. pp. 84-106. Disponível em:

<http://www.uel.br/revistas/uel/index.php/geografia/article/view/9826/8632>. Acesso em: 18/01/2018.

COMISSÃO ECONÔMICA PARA AMÉRICA LATINA E O CARIBE [CEPAL]. Anuario Estadístico de América Latina y el Caribe. Santiago del Chile: Nações Unidas, 2012. Disponível em:

<http://www.eclac.cl/publicaciones/xml/4/48864/AnuarioEstadistico2012_ing.pdf>. Acesso em: 08 de julho de 2013.

COMISSÃO PRÓ-ÍNDIO DE SÃO PAULO [CPI-SP]. Terras em processo por UF: Santa Catarina. CPI-SP [online], sem data. Disponível em:

<http://www.cpisp.org.br/terras/asp/terras_mapa.aspx?UF=sc\&VerTerras=r>. Acesso em: 04/10/2017.

CONSELHO PASTORAL DOS PESCADORES [CPP]. Conflitos Socioambientais e Violações de Direitos Humanos em Comunidades Tradicionais Pesqueiras no Brasil. Brasília/Olinda: CPP, 2016.

CRENSHAW, Kimberlé. On Intersectionality: Essential Writings. Nova lorque: The New Press, 2017.

CUNHA, Manuela Carneiro da; ALMEIDA, Mauro W. B. Populações Tradicionais e Conservação Ambiental. In: CAPOBIANCO, João Paulo et al. (org.). Biodiversidade na Amazônia Brasileira: avaliação e ações prioritárias para a conservação, uso sustentável e repartição de benefícios. São Paulo: Estação Liberdade - Instituto Socioambiental, 2001, pp. 184-193. 
DARELLA, Maria Dorothea Post. A Presença Guarani no Litoral de Santa Catarina: breve informe. Curitiba: Campos (UFPR), v. 4, n.04, pp. 203-205, 2003. Disponível em: <http://revistas.ufpr.br/campos/article/viewFile/1605/1353>. Acesso em: $11 / 01 / 2018$.

DIEGUES, Antonio Carlos (org.). Os Saberes Tradicionais e a Biodiversidade no Brasil. São Paulo: MMA, COBIO, NUPAUB, 2000.

FERNANDES, Ricardo; BUSTOLIN, Cindia; TEIXEIRA, Luana. São Roque. In: LEITE, Ilka Boaventura. Quilombos no Sul do Brasil: Perícias Antropológicas. Florianópolis: Boletim Informativo Núcleo de Estudos de Identidade e Relações Interétnicas (NUER), v.3, n.3, 2006, pp. 131-185.

FERNANDES, Ricardo Cid; PIOVEZANA, Leonel. Perspectivas Kaingang sobre o direito territorial e ambiental no sul do Brasil. Ambiente \& Sociedade (Online), v. 18, 2015, pp. 111-132. Disponível em: <http://www.scielo.br/pdf/asoc/v18n2/pt_1414-753Xasoc-18-02-00111.pdf >. Acesso em: 10/01/2018.

FILHO, Aderval Costa. O Processo de Construção dos Povos e Comunidades Tradicionais no Brasil. Kooperation Brasilien [KoBra] [online], 05/11/2015. Disponível em: <https://www.kooperation-brasilien.org/de/themen/menschenrechtegesellschaft/traditionelle-voelker-gemeinschaften/o-processo-de-construcao-dospovos-e-comunidades-tradicionais-no-brasil>. Acesso em: 15/09/2017.

FLORIT, Luciano Félix. Conflitos ambientais, desenvolvimento no território e conflitos de valoração: considerações para uma ética ambiental com equidade social. Desenvolvimento e Meio Ambiente. Vol 36, abril 2016, pp. 255-271. Disponível em: <http://revistas.ufpr.br/made/article/view/41624>. Acesso em: 09/02/2018.

FLORIT, Luciano Félix. Dos conflitos ambientais à ética socioambiental: um olhar a partir dos povos e comunidades tradicionais. Desenvolvimento e Meio Ambiente. Vol. 52, dezembro de 2019, pp. 261-283. Disponível em: <https://revistas.ufpr.br/made/article/view/59663>. Acesso em 12/08/2020.

FLORIT, L. F.; OLIVEIRA, L. B.; FLEURI, R. M.; WARTHA, R. Índios do Vale Europeu. Justiça ambiental e território no Sul do Brasil. Novos Cadernos NAEA, v. 19, n. 2, 2016, pp. 21-41. Disponível em: <http://www.periodicos.ufpa.br/index.php/ncn/article/view/2478>. Acesso em: $12 / 03 / 2018$.

FÖETSCH, Alcimara Aparecida. Faxinais e Caívas: identidades territoriais na região do Contestado (PR/SC). Tese (Doutorado em Geografia) - Universidade Federal do Paraná, Curitiba, 2014.

FÖETSCH, Alcimara Aparecida; SCHWARZER, Camila. Identidades Territoriais na Região do Contestado (PR/SC). In: Encontro Nacional de Geografia Agrária: Ajuste Espacial X Soberania(s): A Multiplicidade das Lutas e Estratégias de Reprodução no 
Campo, 2016, Aracaju/Sergipe. Anais do Encontro Nacional de Geografia Agrária Ajuste Espacial X Soberania(s): A Multiplicidade das Lutas e Estratégias de Reprodução no Campo. Aracaju/Sergipe: Editora da UFS, 2016. v. 1. pp. 1-15. Disponível em: <http://enga.com.br/anais/index.php>. Acesso em: 30/10/2017.

FUNDAÇÃO CULTURAL PALMARES [FCP]. Comunidades Remanescentes de Quilombos (CRQ's). FCP [online], 2017. Disponível em: <http://www.palmares.gov.br/file/2017/09/CERTID\%C3\%95ES-EXPEDIDAS-\%C3\%80SCOMUNIDADES-REMANESCENTES-DE-QUILOMBOS-12-09-2017.pdf>. Acesso em: $27 / 09 / 2017$.

FUNDAÇÃO OSWALDO CRUZ [FIOCRUZ]. Mapa envolvendo injustiça ambiental e saúde no Brasil: resumo dos resultados iniciais (março de 2010). Fiocruz [online], 2010. Disponível em:

<https://www.conflitoambiental.icict.fiocruz.br/index.php?pag=resumo >. Acesso em: 10/04/2018.

FUNDAÇÃO OSWALDO CRUZ [FIOCRUZ]. Mapa envolvendo injustiça ambiental e saúde no Brasil. Fiocruz [online], sem data. Disponível em:

<https://www.conflitoambiental.icict.fiocruz.br/index.php?pag=resumo $>$. Acesso em: 13/04/2020.

FUNDAÇÃO NACIONAL DO ÍNDIO [FUNAI]. Terras Indígenas. FUNAI [online], sem data. Disponível em: <http://www.funai.gov.br/index.php/indios-no-brasil/terrasindigenas $>$. Acesso em: 24/05/2017.

GARUVA. Lei Ordinária 1981/2017. Prefeitura Municipal de Garuva, 28/04/2017.

GUDYNAS, Eduardo. Ecología, Economía y Ética del Desarrollo Sostenible. Coscoroba Ediciones. 5 a edición revisada, 2004.

GUDYNAS, Eduardo. O novo extrativismo progressista na América do Sul: teses sobre um velho problema sob novas expressões. In: LÉNA, Philippe; NASCIMENTO, Elimar Pinheiro do. Enfrentando os limites do crescimento: sustentabilidade, decrescimento e prosperidade. Rio de Janeiro: Garamond, 2012, pp. 303-318.

GRAVA, Diego da Silva. Naturezas, sustentabilidades e desenvolvimento na modernidade brasileira. Tese (Doutorado em Sociologia) - Programa de PósGraduação em Sociologia, Instituto de Estudos Sociais e Políticos, Universidade do Estado do Rio de Janeiro, Rio de Janeiro, 2017.

GRAVA, Diego da Silva; FLORIT, Luciano Félix; ANTUNES, Douglas Ladik. Cipozeiras e Cipozeiros da Mata Atlântica e Conflitos Ambientais Territoriais em Santa Catarina. Novos Cadernos NAEA, v. 22, n. 2, maio/ago de 2019, pp. 69-92.

HERCULANO, Selene. Riscos e desigualdade social: a temática da Justiça Ambiental e sua construção no Brasil. I Encontro ANPPAS, Indaiatuba, São Paulo, GT Teoria e 
Ambiente, outubro de 2002. Disponível em:

<http://anppas.org.br/encontro_anual/encontro1/gt/teoria_meio_ambiente/Selene\% 20Herculano.pdf $>$. Acesso em: 17/02/2012.

INSTITUTO BRASILEIRO DE GEOGRAFIA E ESTATÍSTICA [IBGE]. Censo Demográfico 2010: Características Gerais dos Indígenas. Rio de Janeiro: IBGE, 2010. Disponível em: <http://biblioteca.ibge.gov.br/visualizacao/periodicos/95/cd_2010_indigenas_univers o.pdf $>$. Acessado em: 18/12/2015.

KNOX, Winifred; TRIGUEIRO, Aline (org.). Saberes, Narrativas e Conflitos na Pesca Artesanal. Vitória: Edufes, 2015.

KUMMROW, Aline. Cafuzos tentam manter a cultura em José Boiteux. Diário do Alto Vale [online], 25/11/2013. Disponível em: <https://www.diarioav.com.br/cafuzostentam-manter-a-cultura-em-jose-boiteux/>. Acesso em: 30/01/2018.

LACERDA, Eugenio Pascele. O Atlântico Açoriano: uma antropologia dos contextos globais e locais da açorianidade. Tese (Doutorado em Antropologia Social), Universidade Federal de Santa Catarina, Florianópolis, 2003. Disponível em: <https://repositorio.ufsc.br/bitstream/handle/123456789/85134/194387.pdf?sequenc e=1\&isAllowed=y $>$ Acesso em: 07/02/2018.

LASCHEFSKI, Klemens. Licenciamento e equidade ambiental. As racionalidades distintas de apropriação do ambiente por grupos subalternos. In: ZHOURI, Andréa (org.). As tensões do lugar. Hidrelétricas, sujeitos e licenciamento ambiental. Belo Horizonte: Editora UFMG, 2011.

LEFF, Enrique. La Ecología Política en América Latina: un campo en construcción. Brasília: Sociedade e Estado, v. 18, n. 1/2, jan./dez. 2003, pp. 17-40. Disponível em: <http://www.scielo.br/pdf/se/v18n1-2/v18n1a02.pdf>. Acesso em: 03/01/2017.

LEFF, Enrique. Racionalidad Ambiental: La reapropiación social de la naturaleza. Ciudad de México, Buenos Aires: Siglo Veintiuno, 2004.

LEITE, Ilka Boaventura. Humanidades Insurgentes: conflitos e criminalização dos Quilombos. In: ALMEIDA, Alfredo Wagner Berno. Territórios Quilombolas e Conflitos. Caderno De Debates Nova Cartografia Social, Vol. 01, №. 02, 2010, pp. 1841.

LIPIETZ, Alain. A Ecologia Política, solução para a crise da instância política? In: ALIMONDA, Héctor (editor). Ecología política. Naturaleza, sociedad y utopía. Buenos Aires: Clacso, 2002, pp. 15-26. Disponível em: <http://www.ceapedi.com.ar/imagenes/biblioteca/libros/326.pdf>. Acesso em: 22/12/2016.

LITTLE, Paul. Territórios e Povos Tradicionais no Brasil: Por uma Antropologia da Territorialidade. Rio de Janeiro: Tempo Brasileiro, 2004, pp. 251-290. Disponível em: 
<http://www.dan.unb.br/images/pdf/anuario_antropologico/Separatas\%2020022003/2002-2003_paullittle.pdf>. Acesso em: 24/08/2017.

MARTÍNEZ-ALIER, Joan. El Ecologismo de los Pobres: conflictos ambientales y lenguajes de valoración. Icaria: Antrazyt-Flacso, $2^{\text {a }}$ edição, 2006.

MARTÍNEZ-ALIER, Joan. O ecologismo dos pobres. São Paulo: Contexto, 2007.

MARTINS, José de Souza. Fronteira: a degradação do outro nos confins do humano. São Paulo: Contexto, $2^{a}$ edição, 2009 [1997].

MARTINS, Pedro Antonio Batista. Anjos de cara suja: etnografia da comunidade cafuza. Dissertação (Mestrado em Antropologia Social), Universidade Federal de Santa Catarina, Florianópolis, 1991. Disponível em:

<https://repositorio.ufsc.br/handle/123456789/75745>. Acessado em: 29/01/2018.

MELLO, Anna Jacinta Machado; PERONI, Nivaldo. Cultural landscapes of the Araucaria Forests in the northern plateau of Santa Catarina, Brazil. J Ethnobiol Ethnomed, 09/06/2015. Disponível em: <https://www.ncbi.nlm.nih.gov/pmc/articles/PMC4489030/>. Acesso em: 18/01/2018.

MOMBELLI, Raquel. Comunidades quilombolas em Santa Catarina: resistência negra e luta pela terra. In: José Carlos Radin. (Org.). História da Fronteira Sul. Porto Alegre, RS: Letra\&Vida, 2015, v. 1, pp. 130-145.

NASSIF, André. Há evidências de desindustrialização no Brasil? Rev. Econ. Polit. [online]. 2008, vol.28, n.1, pp. 72-96.

NEGRI, Fernanda de; ALVARENGA, Gustavo Varela. A primarização da pauta de exportações no Brasil: ainda um dilema. In: INSTITUTO DE PESQUISA ECONÔMICA APLICADA [IPEA]. Radar: Tecnologia, Produção e Comércio Exterior, 2011, pp. 7-14. Disponível em: <http://www.ipea.gov.br/portal/images/stories/PDFs/radar/110509_radar13.pdf>. Acesso em: 23/02/2018.

NEIRA, Juan Carlos Aguirre; DARELLA, Maria Dorothea Post; FANTINI, Alfredo Celso. Os Guarani em Santa Catarina: uma 'minoria inconveniente'? Campina Grande: Tellus, ano 9, n. 16, jan./jun. de 2009, pp.127-148. Disponível em: <http://tellus.ucdb.br/index.php/tellus/article/view/181>. Acessado em: 11/01/2018.

OBSERVATÓRIO DE CONFLITOS AMBIENTAIS [OCA]. Mapa dos Conflitos Ambientais. OCA [online], sem data. Disponível em: $<$ http://conflitosambientaismg.lcc.ufmg.br/observatorio-de-conflitosambientais/mapa-dos-conflitos-ambientais/>. Acesso em: 26/04/2018.

PORTO-GONÇALVES, Carlos Walter. A Ecologia Política na América Latina: Reapropriação Social da Natureza e Reinvenção dos Territórios. Florianópolis: 
Interthesis, vol. 9, n. 1, jan/jun. 2012, pp. 16-50. Disponível em: <https://periodicos.ufsc.br/index.php/interthesis/article/view/18071384.2012v9n1p16/23002>. Acessado em: 03/01/2017.

PORTO-GONÇALVES, Carlos Walter; LEFF, Enrique. Political Ecology in Latin America: the Social Re-Appropriation of Nature, the Reinvention of Territories and the Construction of an Environmental Rationality. Desenvolvimento e Meio Ambiente, Vol. 35, dezembro 2015, pp. 65-88. Disponível em: <http://revistas.ufpr.br/made/article/viewFile/43543/27087>. Acessado em: 26/10/2016.

SCHNEIDER, Sérgio. Teoria social, agricultura familiar e pluriatividade. Revista Brasileira de Ciências Sociais, São Paulo, v. 18, n.51, 2003, pp. 99-121.

SECRETARIA DE POLÍTICAS DE PROMOÇÃO DA IGUALDADE RACIAL DA PRESIDÊNCIA DA REPÚBLICA [SEPPIR-PR]. Territórios Quilombolas. SEPPIR-PR [online], outubro de 2014. Disponível em: <http://monitoramento.seppir.gov.br/paineis/pbq/mapas.vm?type=quilombola\&id=1 $>$. Acesso em: 17/01/2018.

SILVA, Ronnie Aldrin. As 26 principais violações ao meio ambiente feitas por Jair Bolsonaro. Carta Capital, 11 de fevereiro de 2020. Disponível em:

<https://www.cartacapital.com.br/blogs/brasil-debate/as-26-principais-violacoes-aomeio-ambiente-feitas-por-jair-bolsonaro/>. Acesso em: 13/04/2020.

SVAMPA, Maristella. "Consenso de los Commodities" y lenguajes de valoración en América Latina. Nueva Sociedad: março-abril de 2013. Disponível em: <http://nuso.org/articulo/consenso-de-los-commodities-y-lenguajes-de-valoracionen-america-latina/>. Acesso em: 30/05/2017.

ZHOURI, Andréa; LASCHEFSKI, Klemens. Desenvolvimento e Conflitos Ambientais: um novo campo de investigação. In: ZHOURI, Andréa; LASCHEFSKI, Klemens (org.). Desenvolvimento e Conflitos Ambientais. Belo Horizonte: Ed. UFMG, 2010, v. 1, pp. 11-33.

Diego da Silva Grava. Doutor em Sociologia pelo Instituto de Estudos Sociais e Políticos da Universidade do Estado do Rio de Janeiro (Iesp-Uerj). Pesquisador colaborador da Universidade Regional de Blumenau (Furb). Rua Farani, 3, apto 312, CEP 22231-020, Rio de Janeiro - RJ. E-mail: diego.grava@gmail.com

Luciano Félix Florit. Doutor em Sociologia pela Universidade Federal do Rio Grande do Sul (UFRGS). Professor da Universidade Regional de Blumenau (Furb). Rua Ary Taborda Ribas, 333, CEP 89053-520, Blumenau - SC. E-mail: lucianoflorit@gmail.com 
Como citar: DA SILVA GRAVA, Diego; FÉLIX FLORIT, Luciano. Povos e comunidades tradicionais em Santa Catarina: sistematização de dados e reflexão sobre conflitos ambientais territoriais. Redes (St. Cruz Sul, Online), Santa Cruz do Sul, v. 25, p. 1738-1763, nov. 2020. ISSN 1982-6745. doi:https://doi.org/10.17058/redes.v25i4.13431.

\section{CONTRIBUIÇÃO DE CADA AUTOR}

a. Fundamentação teórico-conceitual e problematização: Diego da Silva Grava e Luciano Félix Florit.

b. Pesquisa de dados e análise estatística: Diego da Silva Grava.

c. Elaboração de figuras e tabelas: Patrícia Scaburri (2018) do Labgeo-Furb, a partir de dados informados pelos autores.

d. Fotos: não se aplica

e. Elaboração e redação do texto: Diego da Silva Grava e Luciano Félix Florit.

f. Seleção das referências bibliográficas: Diego da Silva Grava e Luciano Félix Florit.

Fontes de financiamento: Este trabalho é oriundo de pesquisa que contou com o apoio da Coordenação de Aperfeiçoamento de Pessoal de Nível Superior (Capes, bolsa PNPD-Capes), do Conselho Nacional de Desenvolvimento Científico e Tecnológico (CNPq), da Fundação de Amparo à Pesquisa e Inovação do Estado de Santa Catarina (Fapesc) e da Associação Catarinense das Fundações Educacionais (Acafe).

\section{Os autores agradecem:}

A Patrícia Scaburri e ao Labgeo-Furb, pela assistência para a confecção do mapa; Aos pareceristas anônimos que contribuíram com boas sugestões; Aos pesquisadores/as Alcimara Föetsch, Anésio Marques, Cristhine Fabiola Ramos, Douglas Ladik Antunes, Georgia Fontoura, Moyses Berndt, Raquel Mombelli e Vandreza Amante Gabriel, que auxiliaram para viabilizar o trabalho de campo em andamento nas comunidades;

Agradecimento especial às famílias e membros das comunidades que generosamente nos receberam. 